Original scientific paper

\title{
DESIGN AND KEY PROCESS SIMULATION OF A NEW TYPE OF PIPE BENDING UNIT
}

\author{
Qian, S. .,**; Bai, Z. H. ${ }^{* * * *, \# ; ~ H u, ~ W . ~ T . * ; ~ L i n, ~ W . * ; ~ W a n g, ~ T . ~ L . ~}{ }^{*} \&$ Zhang, J. S. \\ * National Cold Rolling Strip Equipment and Process Engineering Technology Research Center of \\ Yanshan University, Qinhuangdao, 066004, China \\ ${ }^{* *}$ Huangshan University College of Mechanical and Electrical Engineering, Huangshan, 245041, \\ China \\ ${ }^{* * *}$ State Key Laboratory of Metastable Materials Science and Technology, Yanshan University, \\ Qinhuangdao, 066004, China \\ E-Mail: bai_zhenhua@aliyun.com ("Corresponding author)
}

\begin{abstract}
The pipe bending mechanism was analysed and a new unit was designed to solve problems of low efficiency and high incidence of defects in large-diameter products. Subsequently, the workflow of the unit was formed, and the finite element model of elbow formation was established. A pipe with $D=$ $60.3 \mathrm{~mm}$ and $t=3.05 \mathrm{~mm}$ was used as an example to simulate the effects of key parameters on the forming quality and determine the optimization parameters. Results show that as clearance increases within in a small range, the flowability of the pipe and the forming quality of the elbow improve. As the surface friction and push-bending speed increase, the quality gradually deteriorates and more defects appear. The mandrel helps enhance the forming quality of the elbow. The wall is thinner in the extrados near the push head but thicker in the intrados near the push head. The obtained conclusions provide a basis for establishing a quantitative relationship between the process parameters of bending machines and forming quality and the comprehensive optimization of the bending machine process. (Received in June 2021, accepted in August 2021. This paper was with the authors 1 month for 1 revision.)
\end{abstract}

Key Words: New-Type Pipe Bending Unit, Finite Element Model, Clearance, Surface Friction, Push-Bending Speed

\section{INTRODUCTION}

As key lightweight components with a large amount and a wide range, pipe bending parts have been widely developed and applied to high-tech industries, such as aerospace, ship, automobile, and energy [1]. However, pipe bending is a complex deformation process with a multifactor coupling effect coupled with the hollow structure of pipes; as such, many quality defects are prone to occur during deformation [2-4]. Therefore, many studies have been conducted on the pipe bending mechanism, the prediction of forming quality, and the proposal of new methods and processes [5-7] to improve the forming quality of common pipes. However, new bending methods and processes have certain limitations. For example, they are only suitable for small batch production under specific conditions of certain pipes.

With the continuous improvement of product quality, new materials are applied, and elbow types are diversified, the high incidence of elbow defects produced by existing forming equipment, especially when the large diameter pipe is formed under the condition of large bending radius, the thickness distribution uniformity of the elbow extrados and intrados is poor, more seriously, the intrados with continuous micro wrinkles, and the extrados with fine cracks, which affect the product quality and directly affect the production efficiency of the unit. However, the influence of key process parameters (such as clearance, surface friction, pushing speed, mandrel) on the forming quality of large-diameter pipes under the condition of a large bending radius has not been systematically studied. In addition, previous studies only measured the forming quality of elbows from the perspective of a plastic strain, which is 
difficult to directly reflect the potential or microquality defects of elbows. In this context, a new type of pipe bending units for large-diameter pipes should be developed.

This study is conducted to design and simulate the forming process of a large-diameter pipe bending machine. A finite element method is applied to simulate the factors affecting the forming quality of the elbow, the distribution of wall thickness and stress is investigated, and the optimal forming process parameters are obtained.

\section{STATE OF THE ART}

Current studies on elbow formation mainly focus on two aspects: the analysis of the mechanism of elbow defects and the factors of the forming quality and numerical calculation that affect pipe bending. Studies on these two aspects can be used as a reference of the present study, and they provide technical support for the design of a new type of pipe bending units.

Some scholars studied the formation mechanism and influencing factors of elbow defects during this process. Song et al. [8] proposed a push bending method assisted by a granular media filler to improve the wrinkle resistance ability of elbows. They also studied the effects of particle diameter, friction between particles, and internal pressure distribution on the forming quality of elbows. Montazeri et al. [9] investigated the forming mechanism of a hydraulic elbow, but the elbow end needs to be closed by using this method, and the forming quality is sensitive to the microdefects of the pipe wall. Oh et al. [10] examined the influence of tube blank shape on forming quality, but they did not explore the influence of process parameters on forming quality. Tabakajew and Homberg and Diekmann et al. [11,12] discussed the influence of mandrel size on the quality of elbows. Guo et al. [13] described the influence of three types of mandrels on the forming quality of an L-shaped elbow. Yang and Lee and $\mathrm{Xu}$ et al. $[14,15]$ proposed an analytical model for a push-bending process in which a joint type mandrel was added to a long-type elbow, and a novel differential lubrication method was proposed to improve the deformation behaviour of L-shaped thin-walled with relative bending radius of 1 in push-bending process. Rihacek et al. [16] analysed the tube ovality and possibilities of its reduction and optimized the pressure distribution on the pipe wall by changing the pressure die geometry; thus, they reduced the ovality of the section. Kazinakis et al. [17] studied the buckling and collapse mechanism of pseudoelastic NiTi structural tube components during bending from the perspective of material geometric nonlinearity, but they did not provide specific methods and measures to avoid or reduce the occurrence of defects. Most scholars considered the influencing factors of elbow defects from the perspective of defect mechanism, but they have not taken multifactor coupling in the actual complex conditions of mass production into account.

Finite element method is applied to predict the bending deformation of elbows. Nguyen et al. [5] considered the geometric parameters of the bending process by Taguchi's orthogonal array and established a finite element model of the copper elbow to predict the forming quality. Jiang et al. [6] studied the rotary drawing formation of a large-diameter thin-walled tube via the finite element method and designed a bionic elastic mandrel for multidie constraints and multiple forming defects. Wu et al. [18] used finite element simulation and five kinds of the experimental mandrel on the quality of the elbow. Huang et al. [19] established a finite element model for the numerical control bending of a Ti-3Al-2.5V tube and provided a reasonable range of process parameters. Liu et al. [20] developed a FEMDEM coupling numerical model to investigate the push-bending process for a thin-wall tube with filled granular media and proposed a simplified formulation for the prediction of the wrinkling of thin-walled elbow tube based on the coupling model. Kami and Dariani [21] combined the artificial neural network and finite element methods to predict the forming quality of bending. Although most scholars investigated the finite element numerical 
calculation of elbow formation to meet the accuracy requirements, they have not applied the calculation results to optimize process parameters under actual working conditions.

In this study, the mechanism of pipe bending was analysed, and a new unit was designed on the basis of a modular design concept. Subsequently, the workflow of the unit was formed, and the finite element model of elbow formation was established. A typical pipe with $D=60.3 \mathrm{~mm}$ and $t=3.05 \mathrm{~mm}$ was described as an example, and the effects of the key parameters on the forming quality of blank pipes were examined. Reasonable optimization parameters were determined.

\section{METHODOLOGY}

\subsection{Principle analysis of cold bending formation}

A blank pipe is slowly pushed through a forming mould via hydraulic rod pushing. Forces on the pipe include the friction $F_{f_{1}}$ between the outer surface of the pipe and the surface of the mould cavity, the friction $F_{f_{2}}$ between the inner surface of the pipe and the outer surface of the mandrel, the axial thrust $F$, and the interaction force $F_{c}$ between the mandrel and the mould. The four forces work together to bend the tube in the mould cavity, and these four forces are equivalent to a pair of bending moments $M$, as shown in Fig. 1.

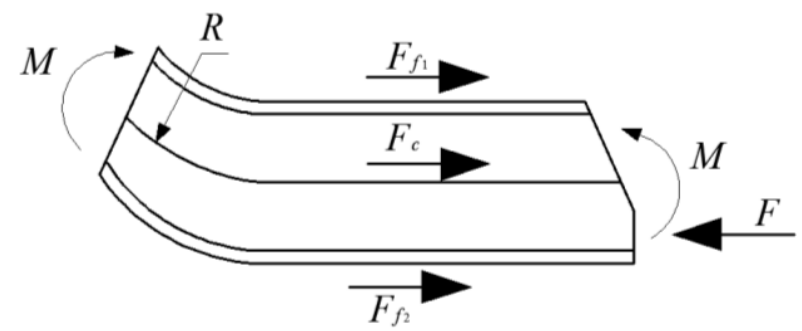

Figure 1: Stress analysis of a blank pipe during bending deformation.

In cold bending, pipe deformation involves three stages: initial elastic deformation, elastic-plastic deformation, and complete plastic deformation. In elbow formation, the outer part is subjected to tangential tensile stress. Consequently, the wall gradually thins. The inner part is compressed tangentially and subjected to tangential compressive stress. Thus, the wall gradually thickens.

The pipe diameter $D$ and the wall thickness $t$ are assumed to be uniform before deformation. The deformation after an external load is applied to the elbow is shown in Fig. 2 a. In the elbow, $\sigma_{\theta}, \sigma_{r}$, and $\sigma_{D}$ are the shear stress, radial stress, and circumferential, respectively. $\varepsilon_{\theta}, \varepsilon_{r}$, and $\varepsilon_{D}$ are the shear strain, the radial strain of the vertical wall thickness, and the circumferential strain along the cross-section of the elbow, respectively. After bending deformation, $\rho_{\lambda}$ is the curvature radius of the strain and stress neutral layers, and $R$ is the bending radius of the pipe after forming. The wall of position $\mathrm{A}$ is the thinnest at the inner part (A in Fig. 2 a refers to as the pipe intrados), and the wall of position B is the thickest at the outer part of the elbow (B in Fig. 2 a refers to as the pipe extrados). The stress and strain states of $\mathrm{A}$ and $\mathrm{B}$ are given in Fig. $2 \mathrm{~b}$.

Several assumptions are made. After bending occurs, the deformed cross-section remains flat. The stress neutral layer coincides with the section centre, and its position remains unchanged. According to the calculation method of elastic-plastic moment $[22,23]$ in other studies, the moment of the pipe section can be simply expressed as Eq. (1).

$$
M=\kappa \varpi \sigma_{b} \sqrt[3]{\frac{D}{\rho_{\lambda}}}
$$


where, $\kappa$ is the coefficient of increase in the bending moment due to friction, $\varpi$ is the coefficient of the bending section, and $\sigma_{b}$ is the tensile strength of materials.

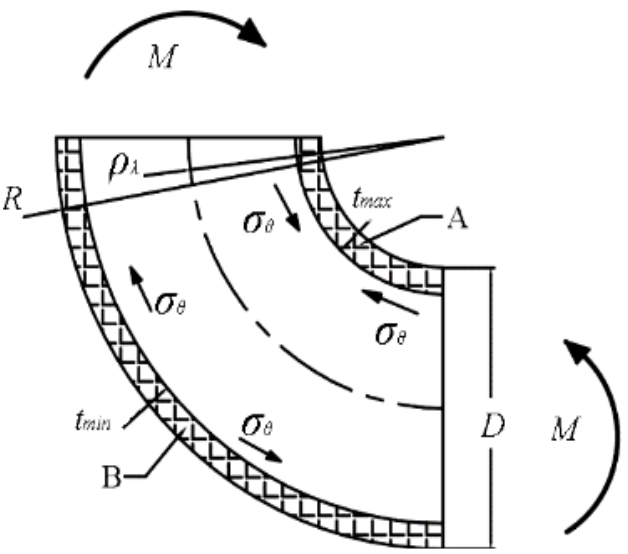

a)

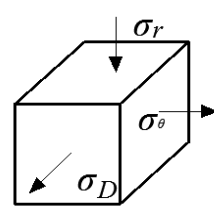

A
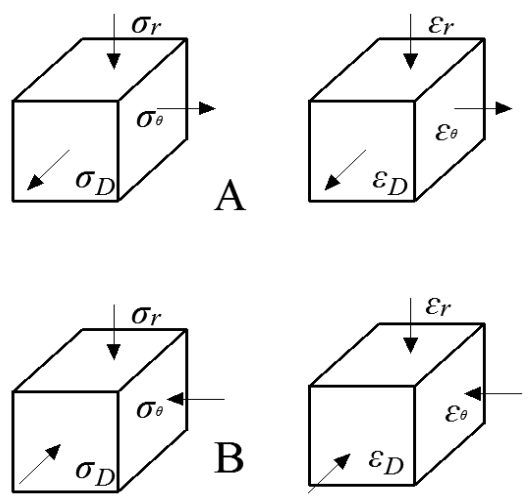

b)

Figure 2: Stress analysis diagram of deformation state: a) deformation of pipe, b) stress and strain states of points $\mathrm{A}$ and $\mathrm{B}$.

At the stage of complete extrusion plastic deformation, the pipe is assumed to be an ideal plastic metal flow [24] according to the principle of constant plastic strain volume, so:

$$
\varepsilon_{\theta}+\varepsilon_{r}+\varepsilon_{D}=0
$$

In the case of small deformation, $\varepsilon_{D}$ is relatively small, which can be ignored and regarded as a plane stress state; $t_{1}$ can be calculated by Eq. (3).

$$
t_{1}=\frac{2 \rho_{\lambda} / D}{2 \rho_{\lambda} / D+1-t / D} t
$$

Thus, the maximum thinning of the wall $\Delta t$ is obtained as follows:

$$
\Delta t=t-t_{1}=t\left(1-\frac{2 \rho_{\lambda} / D}{2 \rho_{\lambda} / D+1-t / D}\right)
$$

\subsection{Design of new-type pipe bending machine}

The new-type pipe bending unit is composed of the hydraulic power mechanism I, guiding mechanism II, positioning mechanism III, bending mechanism IV, and base V. Each part is designed on the basis of the modular design concept (Fig. 3). Fig. 4 shows the bending mechanism that consists of forming moulds (1 and 2), fixed fixture (3), mandrel (4) arranged on the left and right sides of the blank pipe (VI; the pipe), and hydraulic push rod (5).

The workflow of the new type of unit is described as follows. First, the blank pipe is placed on the guide rail of the positioning mechanism such that its central axis is coaxial with that of the mould cavity. Then, the hydraulic power mechanism is started and the hydraulic push rod is pressed. A thrust is formed, which is converted into the bending moment on the right end of the pipe. The pipe is driven by the push rod into the mould of the bending mechanism at a certain speed. The cold push bending method is used to bend the pipe into the target elbow in the forming mould. Lastly, the push rod is reset to its initial state, and the process is complete. 


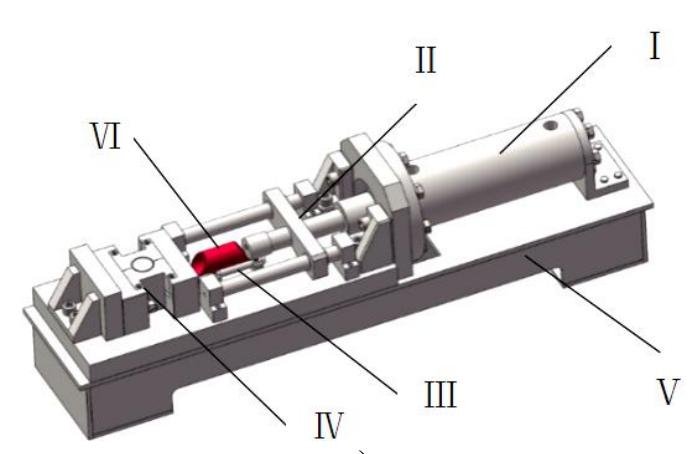

a)

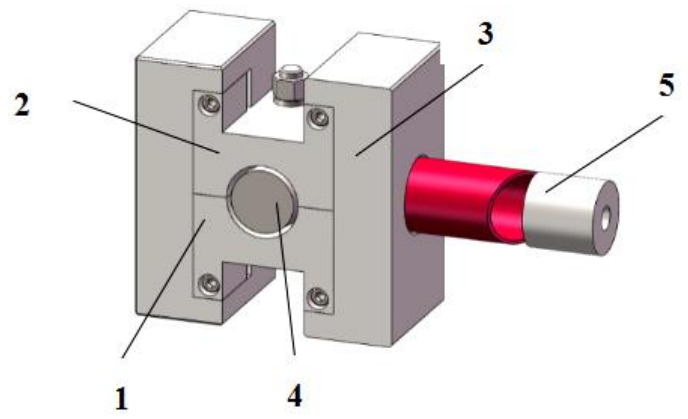

b)

Figure 3: Composition of the new type of pipe bending unit: a) schematic of the assembly of a pipe bending machine, $b$ ) bending mechanism.

$\mathrm{z}_{\mathrm{x}}^{\mathrm{x}}$

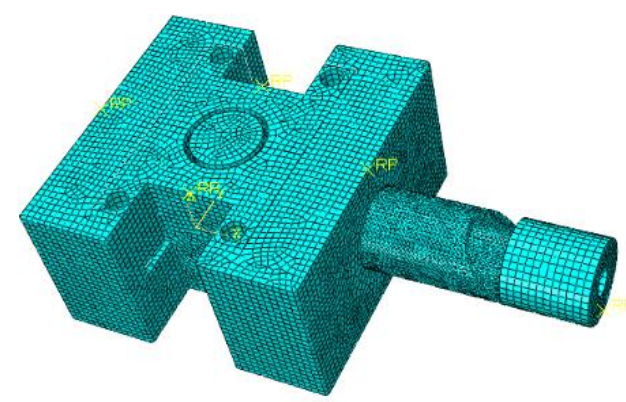

Figure 4: Generation of finite element mesh.

\subsection{Establishment of the model of the elbow}

ABAQUS was used to study the pipe deformation mechanism and its influencing factors in the process of the pipe bending unit. The model was established as follows:

Selection of elements: The pipe and mandrel were selected to be deformed, and the other parts were chosen to be discrete rigid bodies.

Establishment of the geometric models: According to the actual size, the push head, the mandrel, the forming mould, and the blank pipe with $D=60.3 \mathrm{~mm}$ and wall thickness $t=3.05 \mathrm{~mm}$ were established and assembled. The geometric models are shown in Fig. 4.

Setting of the mechanical properties of materials: With its good corrosion resistance and suitability for making pipes and other components, SUS304 stainless steel (0Cr18Ni9; new standard $06 \mathrm{Cr} 19 \mathrm{Ni10}$ ) was selected as the material of the blank pipe. Table I presents the mechanical properties of the material.

Table I: Mechanical properties of SUS304 stainless steel.

\begin{tabular}{|c|c|c|c|c|c|}
\hline $\begin{array}{c}\text { Elastic modulus } \\
(\mathrm{GPa})\end{array}$ & $\begin{array}{c}\text { Yield strength } \\
(\mathrm{MPa})\end{array}$ & $\begin{array}{c}\text { Poisson's } \\
\text { ratio }\end{array}$ & $\begin{array}{c}\text { Density } \\
\left(\mathrm{g} / \mathrm{cm}^{3}\right)\end{array}$ & $\begin{array}{c}\text { Tensile strength } \\
(\mathrm{MPa})\end{array}$ & $\begin{array}{c}\text { Elongation } \\
(\%)\end{array}$ \\
\hline 193 & 272 & 0.29 & 7.93 & 644 & 66 \\
\hline
\end{tabular}

Meshing: The static and general analysis steps were chosen for the model, and the element type of each part was the 10-node modified quadric tetrahedral element C3D10M. Fig. 4 shows the mesh generation.

Boundary conditions: The interaction between the outer wall of the blank pipe and the inner wall of the mould cavity was set as the surface contact, and the contact property was set to penalty, and the friction coefficient was set to $0-0.15$. The interaction between the inner wall of the blank pipe and the outer surface of the mandrel was also set as the surface contact, and the contact property and friction coefficient were set as $0-0.15$. The interaction between 
the hydraulic push rod and the right end of the blank pipe was set as the surface contact. The boundary conditions of the moulds and forming fixtures were completely fixed. The boundary conditions of the hydraulic push rod were established to apply axial velocity, and the speed direction was from the push rod to the mould.

\section{RESULTS AND DISCUSSION}

\subsection{Influencing factors analysis of bending deformation of the blank pipe}

The bending target angle of the blank pipe was constant $(\theta=\pi / 2)$. The bending deformation is affected by various external factors, such as the clearance between the inner wall of the mould cavity and the outer surface of the pipe, the clearance between the inner surface of the pipe and the outer surface of the mandrel, the speed of the hydraulic push rod, the friction between the pipe and the mould surface, the friction between the pipe and the mandrel surface, and the presence of the mandrel in the mould. Fig. 5 shows that $\delta_{1}$ is the clearance between the inner wall of the mould cavity and the outer surface of the pipe, $\delta_{2}$ is the clearance between the inner surface of the pipe and the outer surface of the mandrel, $V_{p}$ is the speed of the hydraulic push rod, and $\mu$ is the friction coefficient of the contact surfaces. These influencing factors on the bending deformation degree were then discussed and analysed.

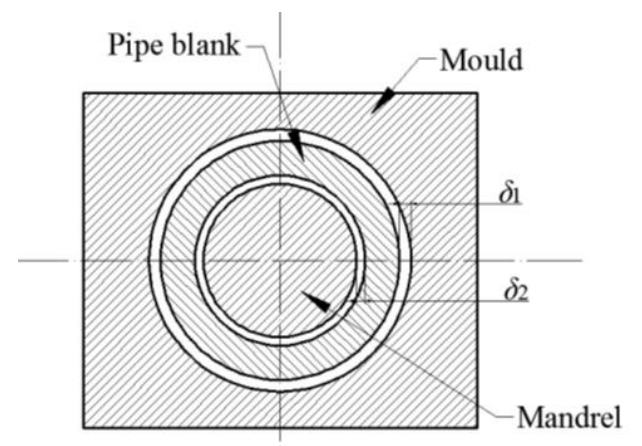

Figure 5: Clearance among mould cavity, blank pipe and mandrel.

\subsection{Clearance influence on the quality of the formed pipe}

Clearance was set to $0.2,0.4,0.6$, and $0.8 \mathrm{~mm}$ under the constant conditions of $V_{p}=150 \mathrm{~mm} / \mathrm{s}$, $\mu=0.05$, and $\delta_{1}=\delta_{2}=\delta$. Fig. 6 shows the finite element calculation results of blank pipe deformation.

Combined with the four equivalent plastic stress maps in Fig. 6, the comparative analysis of the quality of the pipe formed is explained. Under the same conditions, the equivalent plastic stress on the surface of pipe and the stress concentration area decrease as clearance increases. The ductility of the pipe material improves, thereby enhancing flowability and bending quality. The tail end of the elbow with the clearance of $0.2 \mathrm{~mm}$ shows deformation instability compared with that shown in Fig. 6, and a large regional stress concentration is found at the tail end. The essence of this phenomenon is that the deformation resistance of the pipe increases during bending deformation when the clearance is too small, thereby causing difficulty in forming. However, the clearance cannot be set too large. When the clearance is set too large, the plastic stress of the pipe decreases much, which leads to a small depression area appear in the middle of the elbow, as shown in Fig. $6 \mathrm{c}$.

Ten positions were evenly selected on the curved surface of the intrados and the extrados of the elbow to elucidate the thickness distribution of the elbow after forming (Fig. 7). The thickness of the selected points was measured, and their distribution curves were described (Fig. 8). The thickness distribution curves of the intrados surface of the elbow are presented in 
Fig. 8 a. The wall thickness near the push rod is larger than that in other places and exceeds the initial wall thickness of the billet. On the extrados surface of the elbow, the wall near the push head is thinner than that in other places, as shown in Fig. 8 b. However, for the same position, the wall thickness approximately increases as the clearance increases in either the intrados or the extrados surface. The comprehensive analysis shows that the pipe with a clearance of $0.4 \mathrm{~mm}$ has a better forming quality.
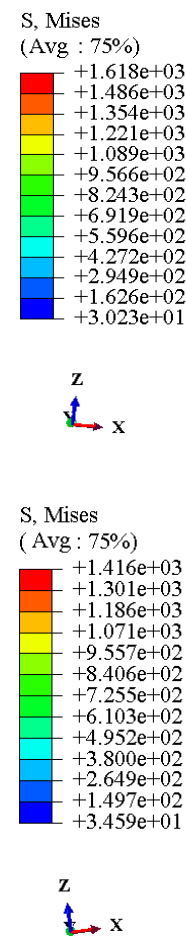

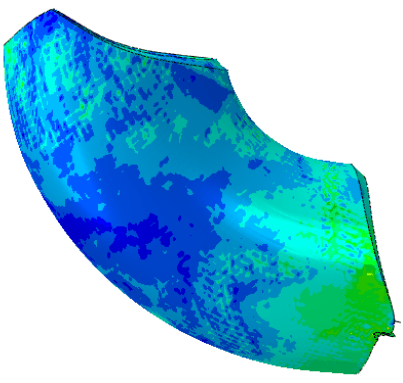

a)

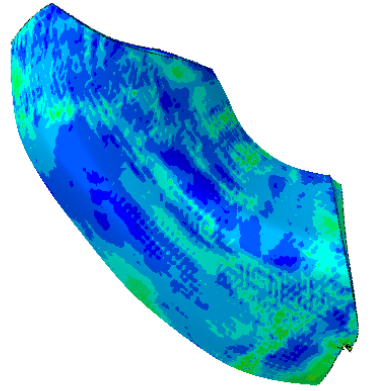

c)

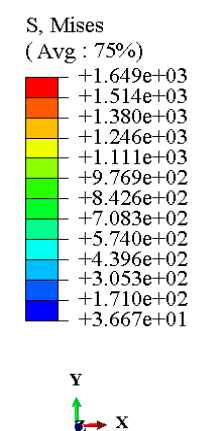

S, Mises

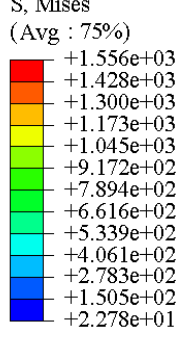

Z $1 \mathrm{x}$

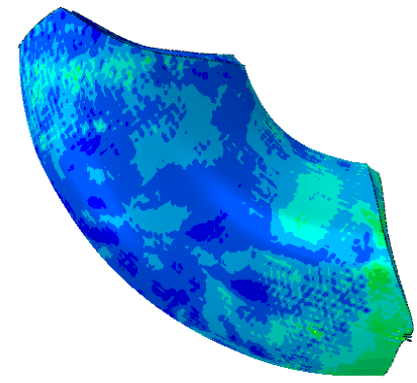

b)

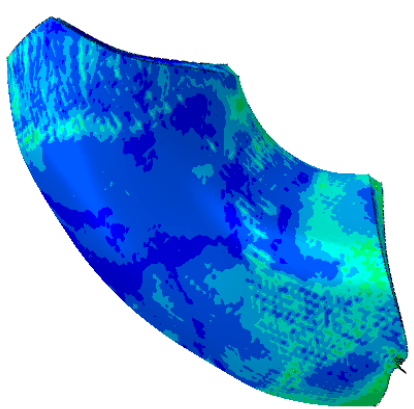

d)

Figure 6: Equivalent plastic strain evolution of the blank pipe under different clearance values: a) $\delta=0.2 \mathrm{~mm}$, b) $\delta=0.4 \mathrm{~mm}$, c) $\delta=0.6 \mathrm{~mm}$, d) $\delta=0.8 \mathrm{~mm}$.

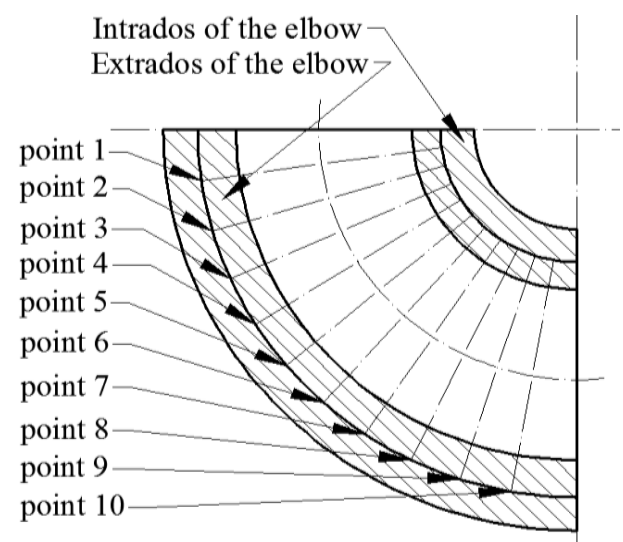

Figure 7: Point location diagram.

\subsection{Friction influence on pipe forming quality}

Under the constant condition of $\delta=0.4 \mathrm{~mm}$ and $V_{p}=150 \mathrm{~mm} / \mathrm{s}, \mu$ was set to $0,0.05,0.10$, and 0.15. The equivalent plastic stress map of the elbow under these different friction conditions is illustrated in Fig. 9. When the surface is smooth, bending deformation is only affected by bending moment. In actual production, this situation does not occur. However, as the friction coefficient between the mould and the pipe increases, the stress concentration area increases and mainly exists at the end of the elbow. At the same time, the deformation and instability of 
the end of the elbow are obvious, resulting in serious uneven thickness at the end of the billet, as shown in Fig. 9 d. The reason for this phenomenon is that the flowability of the pipe material decreases as the friction of the contact surfaces increases, and the contact pressure between the hydraulic push rod and the pipe increases sharply. At the same time, the forming length of the elbow decreases under the same propulsion stroke, resulting in the deformation and instability of the elbow tail. In general, the inner wall of the cavity is smoother, or the lubricant is added onto its surface, which is beneficial to the forming quality of the elbow.

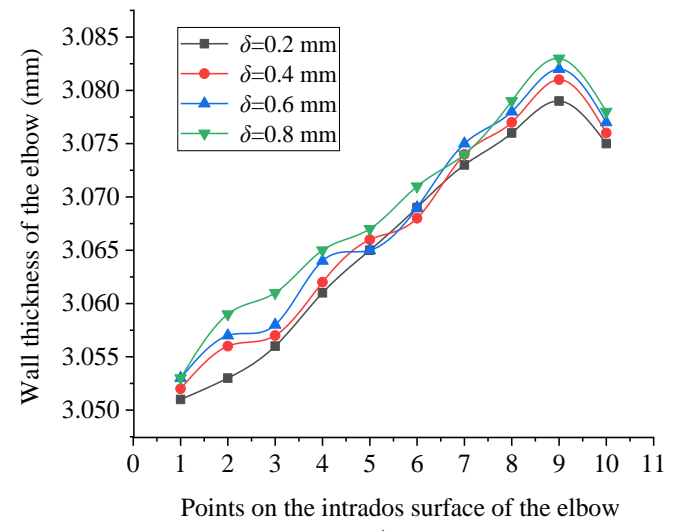

a)

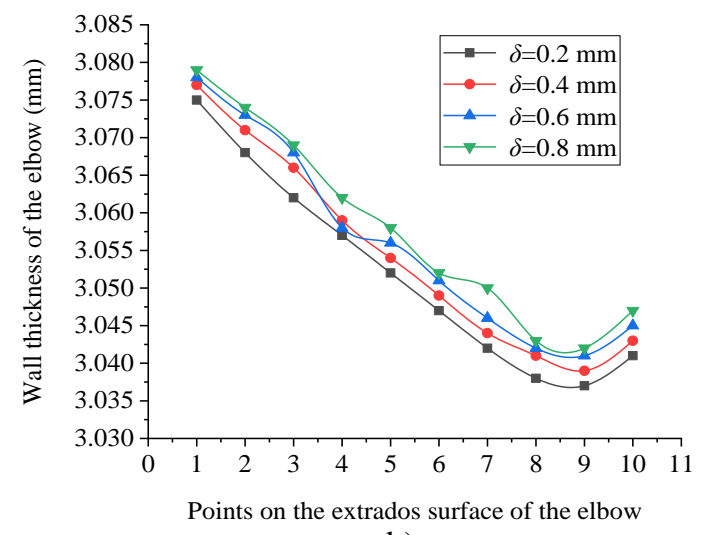

b)

Figure 8: Curves of pipe wall thickness under different clearance values, a) intrados surface, b) extrados surface.

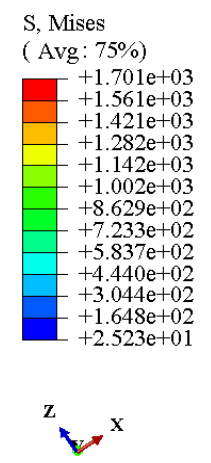

S, Mises (Avg: $75 \%$ )

$+1.590 \mathrm{e}+03$
$+1.459 \mathrm{e}+03$ $+1.328 \mathrm{e}+03$ $+1.197 \mathrm{e}+03$ $+1.066 \mathrm{e}+03$ $.349 \mathrm{e}+02$ $8.038 \mathrm{e}+02$ $6.728 \mathrm{e}+02$
$5.417 \mathrm{e}+02$ $+4.106 \mathrm{e}+02$ $2.796 \mathrm{e}+02$
$1.485 \mathrm{e}+02$ $1.485 \mathrm{e}+02$
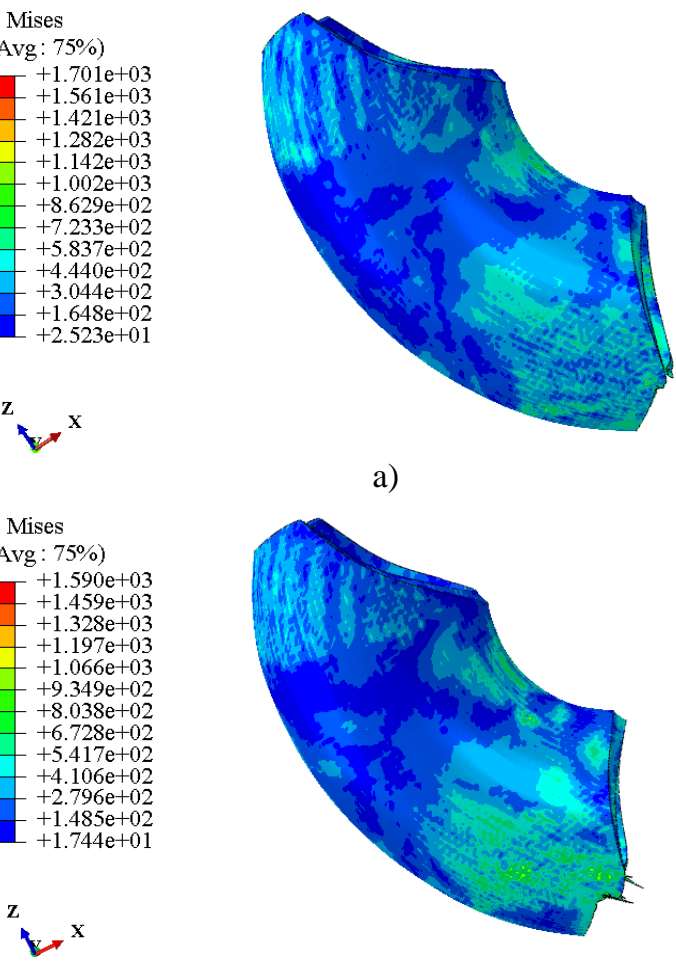

a)

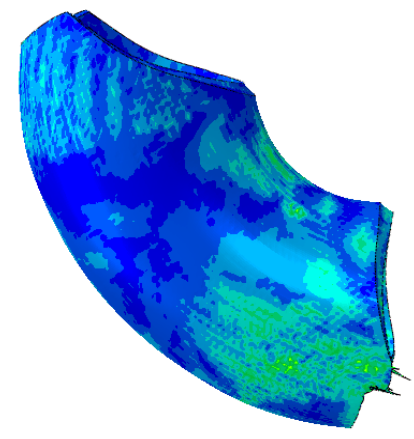

c)

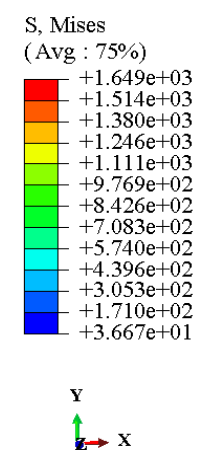

$\mathrm{S}$, Mises

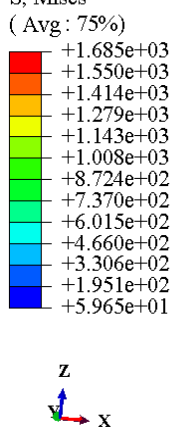

$\stackrel{\mathrm{z}}{\mathrm{L}} \mathrm{x}$

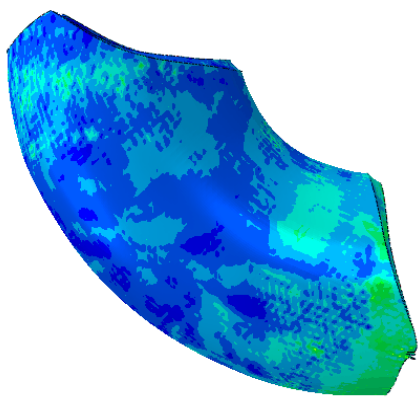

b)

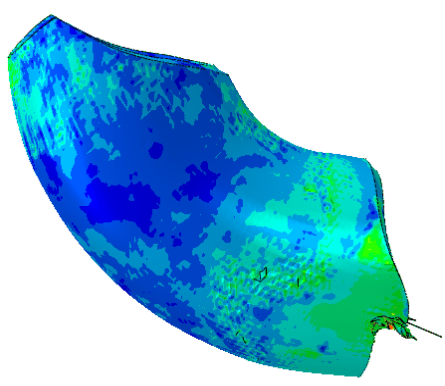

d)

Figure 9: Equivalent plastic strain evolution of the elbow under different friction conditions: a) $\mu=0$, b) $\mu=0.05$, c) $\mu=0.10$, d) $\mu=0.15$.

The influence of surface friction between the inner wall of the mould cavity and the pipe on the forming quality was studied. Similarly, 10 positions were selected, and the wall thickness was calculated. Fig. 10 also shows the thickness distribution pattern similar to that in Fig. 8 (which is not repeated). Therefore, in the forming process, the friction between the mould and the blank pipe should not be too large, so $\mu=0.05$ is more appropriate. 


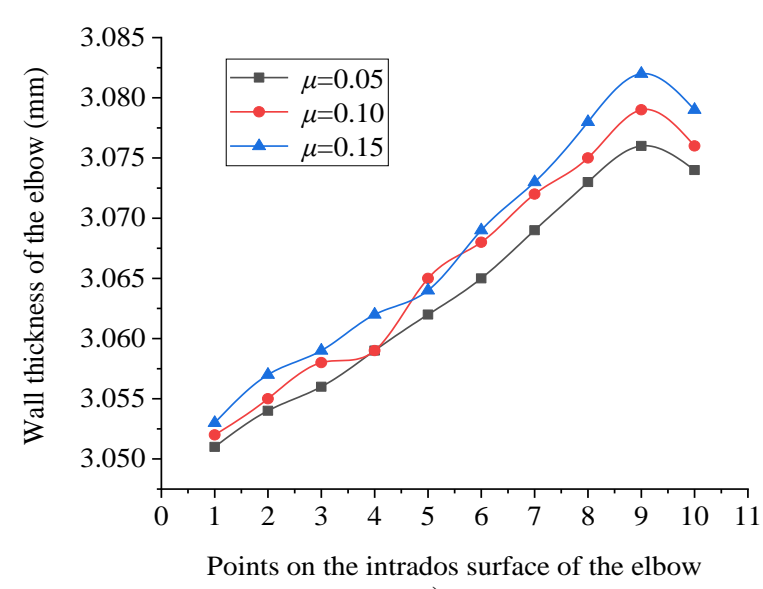

a)

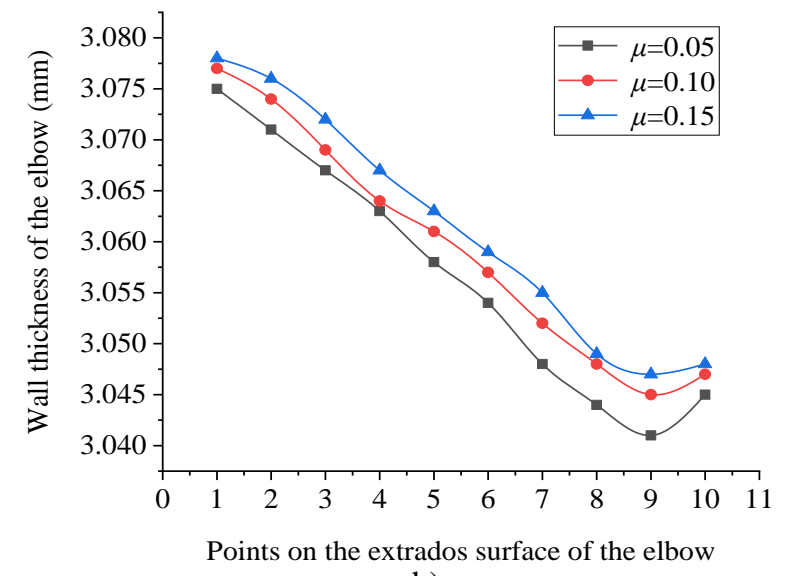

b)

Figure 10: Influence of different frictions on wall thickness distribution, a) intrados surface, b) Extrados surface.

\subsection{Influence of push-bending speed on pipe forming quality}

In the bending deformation of the pipe, $V_{p}$ was set to $150,200,250$, and $300 \mathrm{~mm} / \mathrm{s}$ under the constant conditions of $\delta=0.4 \mathrm{~mm}$ and $\mu=0.05$ ). In Fig. 11 a, at $V_{p}$ of $150 \mathrm{~mm} / \mathrm{s}$, the pushbending speed is low, the deformation of the pipe is relatively stable, and the pipe forming quality is the best. As the bending speed increases, the collision frequency of metal materials in the pipe increases during the formation, possibly disrupting the process stability. In Figs. $11 \mathrm{~b}, 11 \mathrm{c}$, and $11 \mathrm{~d}$, as the bending speed gradually increases, the equivalent plastic stress of the pipe increases, and the area of stress concentration increases. Lastly, the deformation instability of the pipe end results in poor forming quality, thereby increasing the failure rate of the elbow. However, the speed of the push-bending should not be set too small. If the speed is low, it will reduce production efficiency. The bending speed of $150 \mathrm{~mm} / \mathrm{s}$ is the most suitable.

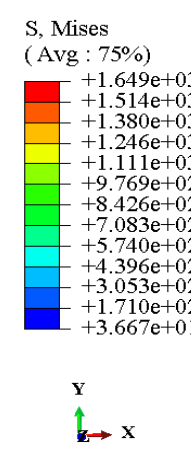

S, Mises

(Avg: $75 \%$ )

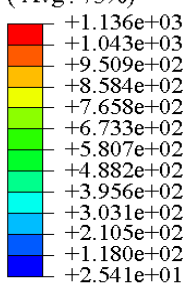

$\mathrm{z}+\mathbf{x}^{\mathrm{x}}$

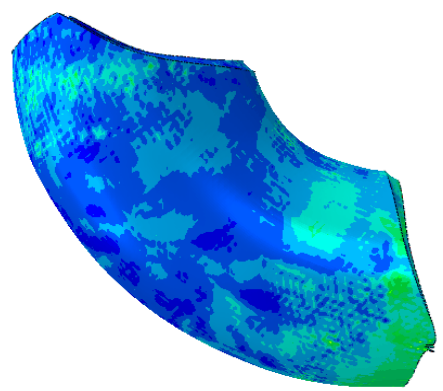

a)

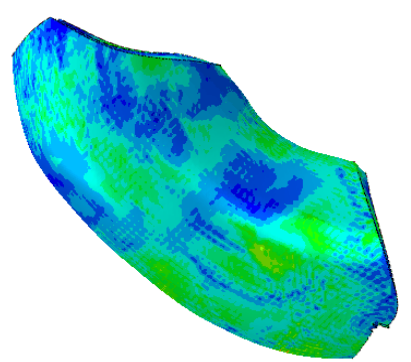

c)
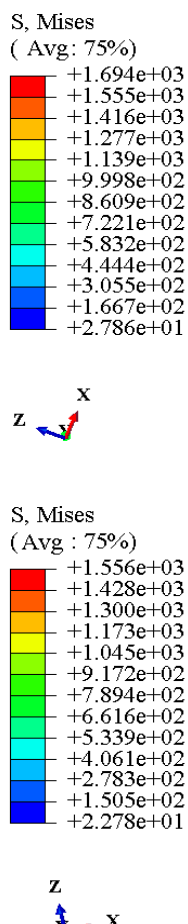

L. $x$

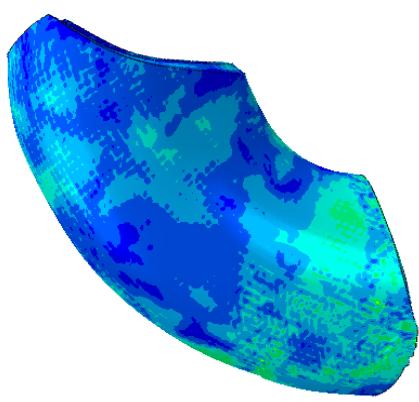

b)

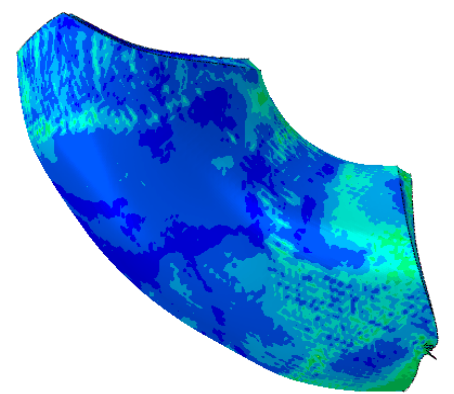

d)

Figure 11: Equivalent plastic strain evolution of the elbow under different push-bending speeds: a) $V_{p}=150 \mathrm{~mm} / \mathrm{s}$, b) $V_{p}=200 \mathrm{~mm} / \mathrm{s} ;$ c) $V_{p}=250 \mathrm{~mm} / \mathrm{s}$, d) $V_{p}=300 \mathrm{~mm} / \mathrm{s}$. 
The influence of push-bending speed on the forming quality of the pipe was studied. Similarly, 10 positions were selected according to Fig. 7. The distribution curves of the wall thickness under different push-bending speeds were plotted. In Fig. 12, the thickness distribution pattern of the points in the extrados and intrados surfaces was similar to those in Figs. 8 and 10 (which is not repeated). However, for the same position on the surface of the pipe, the relationship between wall thickness and push-bending speed is not completely increasing.

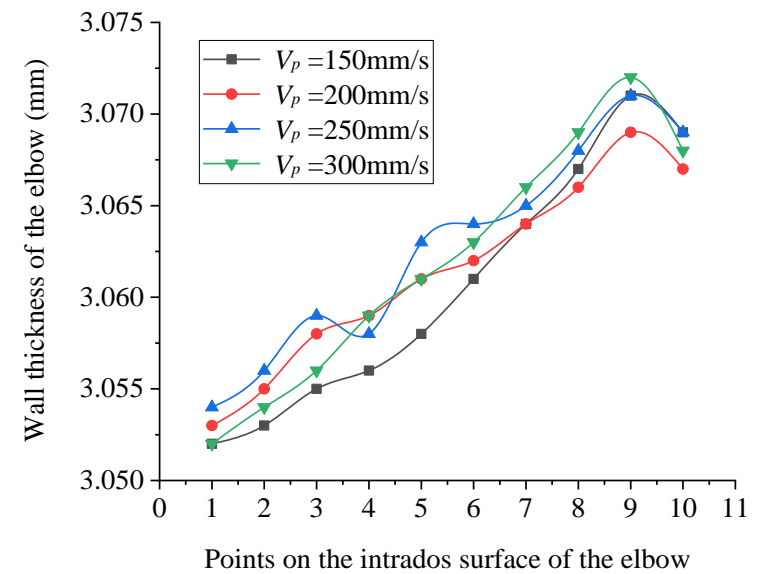

a)

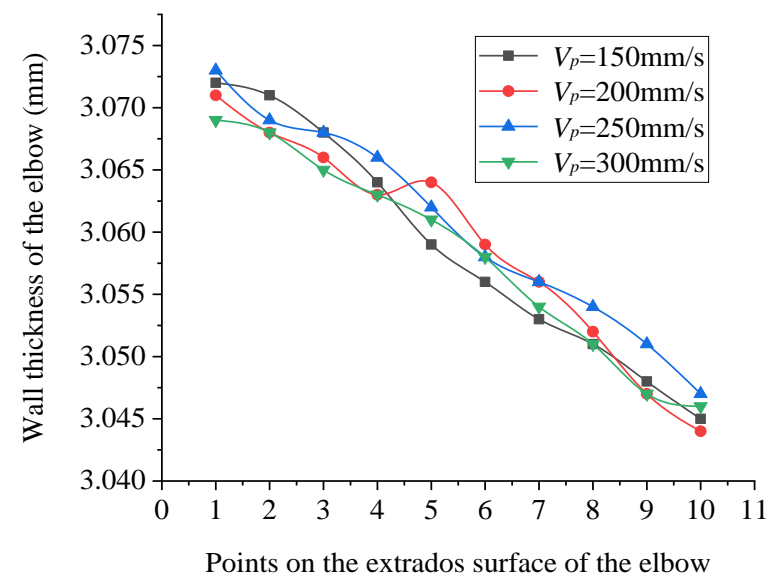

b)

Figure 12: Influence of different push-bending speeds on thickness distribution, a) intrados surface, b) extrados surface.

\subsection{Influence of the mandrel on pipe forming quality}

The mandrel in the forming cavity was used to support the inner wall of the pipe during bending deformation. The final shape of the pipe was determined by the mould. Changes in the pipe forming quality with and without the mandrel were discussed. Figs. $13 \mathrm{a}$ and $13 \mathrm{~b}$ show the simulation results.

In Fig. 13 a, if the mandrel is placed in the pipe, the final shape of the elbow meets the product requirements. However, in Fig. $13 \mathrm{~b}$, when the mandrel is not placed, the elbow has a "dumbbell" shape similar to the thickness of the middle and concave part of the end. These results indicate that the mandrel helps improve the pipe forming quality.

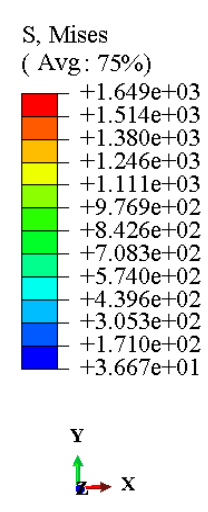

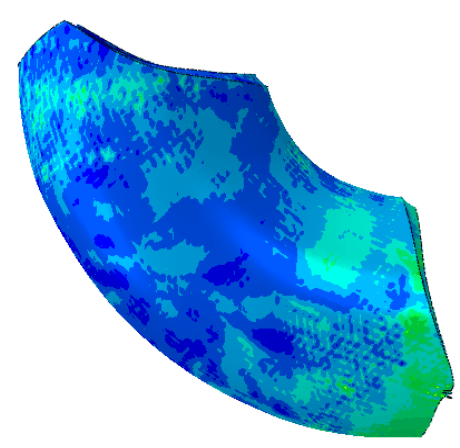

a)

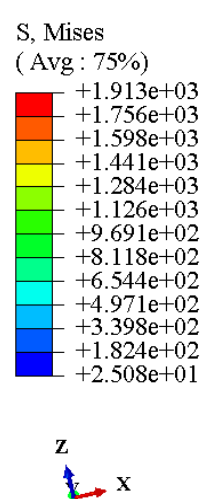

$1 x$

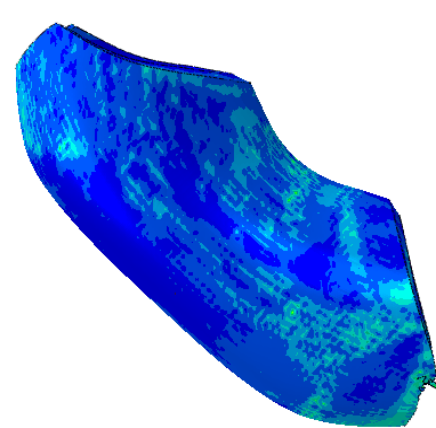

b)

Figure 13: Influence of the mandrel on plastic deformation of pipe forming, a) with a mandrel, b) without a mandrel. 


\section{CONCLUSIONS}

A new type of pipe bending unit was developed on the basis of the modular design concept to improve production efficiency and product quality. The working principle of the equipment was analysed, the production process was formulated, and the finite element model of the elbow was established. The influence of key process parameters on the forming quality of the elbow was studied. The main conclusions are as follows:

(1) In a small clearance range, improving the forming quality of pipe bending is beneficial because the stress concentration area decreases as the clearance among the mould cavity, the pipe, and the mandrel increases.

(2) Reducing the friction among the pipe, the mould and the mandrel is conducive to enhancing the stability of the bending deformation. Likewise, reducing the push-bending speed is favourable to decreasing the incidence of bending defects.

(3) The mandrel helps improve the forming quality of the elbow. The elbow shows that the pipe wall is thinner in the extrados near the push head but thicker in the intrados near the push head.

This study provides a basis for describing the quantitative relationship among the process parameters of a pipe bending unit, forming quality, and the comprehensive optimization of pipe bending. However, the actual working conditions of the pipe bending machine are complex and there are many influencing factors. Therefore, further studies should explore the forming characteristics of elbow through a combination of micro-scale numerical simulations and experiments.

\section{ACKNOWLEDGEMENT}

This work was supported by the Funding Project of Central Guiding for Local Science and Technology Development (206Z1004G), and the Project of Tangshan Science and Technology Plan (20140209C), China.

\section{REFERENCES}

[1] Liu, N.; Yang, H.; Li, H.; Yan, S. (2016). Plastic wrinkling prediction in thin-walled part forming process: A review, Chinese Journal of Aeronautics, Vol. 29, No. 1, 1-14, doi:10.1016/ j.cja.2015.09.004

[2] Michalczyk, J.; Wojsyk, K. (2015). Development and modelling of the method of mandrelless small-radius tube bending, Archives of Metallurgy and Materials, Vol. 60, No. 4, 2797-2803, doi:10.1515/amm-2015-0449

[3] Wang, S. R.; Wang, Z. L.; Gong, J.; Wang, Y. H.; Huang, Q. X. (2020). Coupling effect analysis of tension and reverse torque during axial tensile test of anchor cable, DYNA - Ingenieria $e$ Industria, Vol. 95, No. 3, 288-293, doi:10.6036/9603

[4] Wang, S. R.; Wang, Z. L.; Chen, Y. B.; Wang, Y. H.; Huang, Q. X. (2020). Mechanical performances analysis of tension-torsion coupling anchor cable, International Journal of Simulation Modelling, Vol. 19, No. 2, 231-242, doi:10.2507/IJSIMM19-2-512

[5] Nguyen, D.-T.; Nguyen, D.-T.; Kim, Y.-S. (2015). Improving formability of tube bending for a copper material using finite element simulation, Journal of Mechanical Science and Technology, Vol. 29, No. 10, 4205-4211, doi:10.1007/s12206-015-0915-2

[6] Jiang, L. F.; Zhang, S. Y.; Wang, Y. Q.; Feng, Y. X.; Lin, Y. C.; Liu, H.; Zhang, F.; Shao, H. (2019). Research on bending forming method of large diameter-thickness ratio thin-walled tubes for aerospace, The International Journal of Advanced Manufacturing Technology, Vol. 102, No. 9-12, 3037-3049, doi:10.1007/s00170-019-03328-7

[7] Wang, S. R.; Xiao, H. G.; Hagan, P.; Zou, Z. S. (2017). Mechanical behavior of fully-grouted bolt in jointed rocks subjected to double shear tests, DYNA - Ingenieria e Industria, Vol. 92, No. $3,314-320$, doi: $10.6036 / 8325$ 
[8] Song, H.-W.; Xie, W. L.; Zhang, S.-H.; Jiang, W. H.; Lăzărescu, L.; Banabic, D. (2021). Granular media filler assisted push bending method of thin-walled tubes with small bending radius, International Journal of Mechanical Sciences, Vol. 198, Paper 106365, 11 pages, doi:10.1016/j.ijmecsci.2021.106365

[9] Montazeri, S.; Gorji, A.; Bakhshi, M. (2016). A new method for compression bending of thinwalled tubes in hydro-bending process, The International Journal of Advanced Manufacturing Technology, Vol. 85, No. 1-4, 557-571, doi:10.1007/s00170-015-7910-8

[10] Oh, I. Y.; Han, S. W.; Woo, Y. Y.; Ra, J. H.; Moon, Y. H. (2018). Tubular blank design to fabricate an elbow tube by a push-bending process, Journal of Materials Processing Technology, Vol. 260, 112-122, doi:10.1016/j.jmatprotec.2018.05.017

[11] Tabakajew, D.; Homberg, W. (2017). Increasing the efficiency of hot mandrel bending of pipe elbows, Procedia Engineering, Vol. 207, 2310-2315, doi:10.1016/j.proeng.2017.10.1000

[12] Diekmann, U.; Homberg, W.; Prehm, J.; Rostek, T.; Schönhoff, N.; Tabakajew, D.; Trasca, A.; Uysal, H. (2018). Optimization of tooling design for hot mandrel bending of pipe elbows, Materials Science Forum, Vol. 918, 159-164, doi:10.4028/www.scientific.net/MSF.918.159

[13] Guo, Q.; Ma, F. Y.; Guo, X. Z.; Tao, J. (2018). Influence of mandrel on the forming quality of bending L-shaped hollow parts, The International Journal of Advanced Manufacturing Technology, Vol. 95, No. 9-12, 4513-4522, doi:10.1007/s00170-017-1536-y

[14] Yang, Y.-J.; Lee, C.-M. (2021). A study on the optimization of joint mandrel shape for manufacturing long type elbow using push bending process, International Journal of Precision Engineering and Manufacturing, Vol. 22, No. 3, 431-439, doi:10.1007/s12541-020-00443-4

[15] Xu, X. F.; Fan, Y. B.; Wu, Y. W.; Wu, K. W.; Xiao, J. (2021). A novel differential lubrication method for push-bending of L-shaped thin-walled tube with $1 \mathrm{D}$ bending radius, International Journal of Material Forming, Vol. 14, No. 2, 691-701, doi:10.1007/s12289-020-01563-y

[16] Rihacek, J.; Cisarova, M.; Peterkova, E.; Podany, K. (2021). Influence of the pressure die geometry on the bent tube ovality, MM Science Journal, Vol. 2021, No. 2, 4474-4482, doi:10.17973/MMSJ.2021_6_2021082

[17] Kazinakis, K.; Kyriakides, S.; Jiang, D. J.; Bechle, N. J.; Landis, C. M. (2021). Buckling and collapse of pseudoelastic NiTi tubes under bending, International Journal of Solids and Structures, Vol. 221, 2-17, doi:10.1016/j.ijsolstr.2019.12.017

[18] Wu, C.; Yan, Y.; Hu, Z. L. (2015). Effect of mandrel on the forming quality of thin walled tube, Hydro Mechatronics Engineering, Vol. 43, No. 12, 52-59

[19] Huang, T.; Wang, K.; Zhan, M.; Guo, J. Q.; Chen, X.; Chen, F.; Song, K. (2019). Wall thinning characteristics of Ti-3Al-2.5V tube in numerical control bending process, Journal of Shanghai Jiaotong University (Science), Vol. 24, No. 5, 647-653, doi:10.1007/s12204-019-2079-1

[20] Liu, H.; Zhang, S.-H.; Song, H.-W.; Shi, G.-L.; Cheng, M. (2019). 3D FEM-DEM coupling analysis for granular-media-based thin-wall elbow tube push-bending process, International Journal of Material Forming, Vol. 12, No. 6, 985-994, doi:10.1007/s12289-019-01473-8

[21] Kami, A.; Dariani, B. M. (2011). Prediction of wrinkling in thin-walled tube push-bending process using artificial neural network and finite element method, Proceedings of the Institution of Mechanical Engineers, Part B: Journal of Engineering Manufacture, Vol. 225, No. 10, 18011812, doi:10.1177/0954405411404300

[22] Al-Qureshi, H. A. (1999). Elastic-plastic analysis of tube bending, International Journal of Machine Tools \& Manufacture, Vol. 39, 87-104, doi:10.1016/S0890-6955(98)00012-1

[23] Lu, S. Q.; Fang, J.; Wang, K. L. (2016). Plastic deformation analysis and forming quality prediction of tube NC bending, Chinese Journal of Aeronautics, Vol. 29, No. 5, 1436-1444, doi:10.1016/j.cja.2016.03.009

[24] Basic, H.; Demirdzic, I.; Muzaferija, S. (2020). Calculation of the plastic metal flow in the cold extrusion technology by finite volume method, Technical Journal, Vol. 14, No. 4, 493-498, doi: $10.31803 / \operatorname{tg}-20200811175336$ 